\title{
Peste des Petits Ruminants serological survey in Karamoja sub region of Uganda by competitive ELISA
}

\author{
Bonny Mulindwa ${ }^{1}$, Simon Petter Ruhweza ${ }^{1}$, Chrisostom Ayebazibwe* ${ }^{1}$, Frank Norbert Mwiine ${ }^{2}$, \\ Dennis Muhanguzi ${ }^{2}$ and William Olaho-Mukani ${ }^{1}$ \\ 1. National Animal Disease Diagnostics and Epidemiological Center (NADDEC), Ministry of \\ Agriculture Animal Industry and Fisheries, P. O. Box 513, Entebbe, Uganda. \\ 2. Faculty of Veterinary Medicine, Makerere University, P. O. Box 7062, Kampala, Uganda. \\ * Corresponding Author email: cayebazibwe@gmail.com
}

\begin{abstract}
Following the historical reports of mysterious illnesses and deaths in goats in the Karamoja sub-region in April, 2007 and subsequent confirmation of Pest des Petitis Ruminants in July, 2007; we carried out a serological survey to determine the indicative caprine PPRV exposure rate by 2009. We sampled 280 goats from Moroto, Nakapiripirit, Abim and Kotido Districts of North-eastern Uganda to detect antibodies against PPRV using competitive enzyme linked immunosorbent assay (cELISA). The prevalence of PPRV antibodies in the districts of Moroto, Nakapiripirit, Kotido and Abim was 63.2\% (CI = 95\%, 58.0 - 68.0\%), 72.0\% (CI = 95\%, $65.6-78.4 \%), 85 \%(\mathrm{CI}=95 \%, 81.0-$ $88.9 \%)$ and $1.6 \%(\mathrm{CI}=95 \%,-0.01-3.22 \%)$ respectively. The overall prevalence of antibodies against PPRV in Karamoja sub-region was found to be $57.6 \%(\mathrm{CI}=95 \%, 48.8-66.4 \%)$. The high prevalence of antibodies against PPRV suggests that active infection may still be present and therefore the need to institute disease control measures. More studies should be undertaken to characterize the viruses involved and the epidemiology of PPR in Uganda.
\end{abstract}

Key words: Goats, Competitive (ELISA), Karamoja, Peste des petits ruminants Virus (PPRV), PPRV antibodies.

\section{I ntroduction}

Peste des petits ruminants (PPR) is a contagious viral disease of small ruminants (Furley et al., 1987). The causative virus (PPRV) belongs to the genus Morbillivirus of the family Paramyxoviridae, closely related to the Rinderpest virus of bovines, distemper virus of domestic and wild carnivores (Murphy et al., 1999). It's also closely related to the human measles virus and Morbilliviruses of marine mammals (Yayehrad 1997). Sero-conversion to PPRV by goats and sheep protects in contact bovines from natural infection which may also interfere in tissue culture rinderpest virus (TCRPV) vaccine response (Sudharshan et al., 1995). Peste des petits ruminants, also known as goat plague is of increasing importance in Africa and Asia where small ruminants form an important component of agricultural food production (OIE, 2002). The virus has been circulating in parts of sub Sahara Africa for several decades and in the Middle East and southern Asia since 1993, although the first description of the virus in India dates way back in 1987 (Dhar et al., 2002).

This virus was first reported in West Africa in the early 1940s (Gargadennec et al.,1942) and was later found in Senegal (Gilbert et al,1962) and subsequ- ently recognized as being endemic in west and central Africa (Scott 1981). It has also been reported in Sudan (Taylor 1984) and in East Africa in Kenya (Wamwayi etal., 1995).

In small ruminants, symptoms of sudden depression, fever, nasal and ocular discharges, diarrhea and occasional death are common (Gibbs $e t$ al., 1979). Peste des petits ruminants virus needs close contact between infected and susceptible animals to spread (Lefevre et al., 1994). In Uganda, goats were having severe diarrhea which was not responding to anti-helmentic and antibiotic treatment (P. Panvuga, personal communication). In an attempt to know the exact cause, serum samples from symptomatic goats were subjected to cELISA test which confirmed PPR in Karamoja sub-region. This follow up study was conducted to investigate the seroprevalence of PPR virus many months after the initial evidence of antibodies against PPRV in goats within Karamoja sub-region (MAAIF, 2009).

\section{Materials and methods}

Sampling and sample size determination : There are approximately one million four hundred and ninety nine thousand nine hundred and six estimated 
goats in the Districts of Moroto, Nakapiripirit, Abim and Kotido Districts (MAAIF, 2008).

The seroprevalence of PPR in the districts near those in the current study was recently reported to be about 36\% (Ruhweza et al, 2010). Taking the reference goat population at 1,499,906 (MAAIF, 2008) and the background PPRV seroprevalence to be $36 \%$ (Ruhweza et al., 2010 ) we determined the sample size (n) using Win episcope 2.0 software (http://www.clive.ed.ac.uk/ cliveCatalogueItem.asp?id=B6BC9009-C10F-4393A22D-48F436516AC4) by setting the confidence at $95 \%$ and error term at 5\% on the sample size determination by percentage tab. The sample size was calculated as thus; sampling fraction $=0.024$, sample size $\mathrm{n}=354$, adjusted sample size $n(a)=353$, used value of $\mathrm{n}=353$ goats.

There is high level insecurity in the Karamoja sub region due to animal rustling that has for long defined the lifestyle of the Karamajong and the neighboring Kenyan Pastoral tribes. This is one of the reasons why diseases like PPR still persist in this part of the country. We therefore set out to sample 354 goats in these districts but we could only access 280 goats during the study period. All goats that we came across in the protected kraals (all animals are communally grazed and held in protected kraals in this region) established to minimize animal rustling were sampled. We therefore recognize possible under or over estimation of PPRV antibodies due to taking slightly less goats than were required but to our knowledge this study sets a stage for more exhaustive studies done under more elaborate sampling designs.

Blood samples from the jugular vein were taken from a total of 280 goats. $2 \mathrm{mls}$ of serum were obtained from each goat blood sample and subjected to cELISA test to determine the seroprevalence of PPRV in the four districts (table 1) found in Karamoja sub-region (table 1), North Eastern Uganda. By the time sampling was done, all the animals in the sub-region had not been vaccinated against PPR virus, implying that seropositive animals had been exposed to field infection (Abraham et al., 2005)

Competitive ELI SA (cELISA): Competitive ELISA as previously described by Libeau et al., 1995 and modified by Singh et al. (2002) for PPRV detection was used. This cELISA is reported to have the efficacy similar to that of Virus Neutralisation test (VNT) at detecting PPRV antibodies. As such this ELISA has a very high relative specificity $(98.4 \%)$ and sensitivity $(92.4 \%)$ compared to that of VNT. The sensitivity of c-ELISA for PPR sero-surveillance is even higher $(95.4 \%)$ if the target population is non-vaccinated as the case was for the Karamoja region goats. For this reason we used end-point titration of PPR to detect PPRV antibodies in the 280 goats sampled.

Briefly, rinderpest virus (RPV) antigen stock was reconstituted by addition of RPV antigen stock in coating buffer (1/100). Therefore, 60ul of RPV stock were put in $6 \mathrm{ml}$ of coating buffer. To all ELISA plate wells, $50 \mu 1$ of diluted antigen were added. The plates were then taped to spread the antigen. They were immediately sealed and incubated for one hour at 37 ${ }^{\circ} \mathrm{C}$ on an orbital shaker. Thereafter, the plates were washed three times by filling and emptying the wells with distilled water and blotted to dry on an absorbent paper. Enough blocking buffer was prepared the tests to be done; that is, for one plate; $25 \mathrm{ml}$ of coating buffer was mixed with $25 \mu 1$ Tween 20 and $75 \mu \mathrm{l}$ bovine serum (Negative serum). 40 $\mu 1$ of blocking buffer was added to each of the wells with an extra $10 \mu 1$ in the monoclonal antibody (Mab) control wells (F1, F2, G1 and G2). 10ul of test serum samples were added to each well in duplicate and $10 \mu \mathrm{l}$ of each control sera, that's to say; positive wells B1, B2 and C1, C2, weak positive D1, D2 and E1, E2, Negative control H1and $\mathrm{H} 2$. A working dilution of monoclonal antibody was immediately prepared in the blocking buffer $(1: 100$ dilution i.e. $60 \mu \mathrm{l} \mathrm{Mab}$ in $6 \mathrm{ml}$ blocking buffer; for one plate) and added to $50 \mu \mathrm{l}$ of Mab in all wells of the plate except the conjugate controls. Incubation and washing were repeated as previously described. Before the end of Serum/monoclonal antibody incubation; the working dilution of the conjugate in the blocking buffer sufficient for all micro plates was prepared (approximately 5 minutes before). For one plate $6 \mu 1$ of the conjugate was added to $6 \mathrm{ml}$ blocking buffer. Then, to all wells, $50 \mu \mathrm{l}$ of anti-mouse conjugate in blocking buffer re added.

The resultant preparation was incubated for one hour at $37^{\circ} \mathrm{C}$. After the incubation, the plates were washed three times and blotted to dry. Immediately before the end of the conjugate incubation, a working dilution of the substrate $\left(\mathrm{H}_{2} \mathrm{O}_{2}\right)$ /chromogen (OPD) was prepared. For 2 plates, $48 \mu \mathrm{l}$ of substrate stock $\left(\mathrm{H}_{2} \mathrm{O}_{2}\right)$ in $12 \mathrm{ml}$ of chromogen stock was prepared. The final substrate/ chromogen solution appeared colorless and stored in the dark and if at all it changed color, it was discarded and a fresh one prepared. $50 \mu 1$ of substrate/ chromogen were added to the first column of blanking plate and after that, another $50 \mu 1$ of the substrate/ chromogen was added to the rest of the wells of the plate.

The plates were put on an orbital shaker at room temperature to ensure uniform mixing. All plates were 
Peste des Petits Ruminants serological survey in Karamoja sub region of Uganda by competitive ELISA

Table-1. Seroprevalence of PPRV antibodies in different districts in Karamoja.

\begin{tabular}{lcc}
\hline Karamoja Sub-region Districts & Number of goats sampled/tested & Percentage seropositivity (95\% Cl) \\
\hline Moroto & 87 & $63.2(58.0-68.0)$ \\
Nakapiripirit & 52 & $72.0(65.6-78.4)$ \\
Abim & 61 & $1.6(-0.01-3.22)$ \\
Kotido & 80 & $85.2(81.0-88.9)$ \\
Total & 280 & $57.6(48.8-66.4)$ \\
\hline
\end{tabular}

covered to protect them from excessive light and then allowed to stand at room temperature for 10 minutes for color development. After color development, the reactions are stopped by adding $50 \mu \mathrm{l}$ of stopping solution (1 M sulphuric Acid) to all wells of the test plate and to the first column of the blanking plate. The plates were now ready for reading using an electro photometer at the wavelength of $492 \mathrm{~nm}$.

The intensity of the developed color is directly proportional to the optical density as read by the electro photometer which provided results in form of percentage inhibitions (PI).

$\mathrm{PI}=100-($ Absorbance of the test wells)/(Absorbance of the Mab control wells $) \times 100$

A sample was considered positive if it had a PI value of greater than $50 \%$ and it was considered negative if it had a PI value of less than $50 \%$.

\section{Results and Discussion}

Of the 280 serum samples examined for the presence of PPR virus antibodies from Karamoja subregion, $160(57.6 \%)$ and $120(42.4 \%)$ serum samples were positive and negative for PPRV antibodies respectively.

The seroprevalences of PPR virus antibodies varied between districts of Karamoja sub-region with the highest seroprevalence recorded in Kotido district $85.2 \%(\mathrm{CI}=95 \%, 81.0-88.9)$ and the lowest in Abim district $1.6 \%(\mathrm{CI}=95 \%,-0.01-3.22)$ (Table 1$)$.

This study reveled that approximately over $50 \%$ of all the goats in Karamoja sub-region had circulating antibodies against PPR virus in their blood. The current overall seroprevalence of PPRV antibodies namely; $57.6 \%(\mathrm{CI}=95 \%, 48.8-66.4 \%)$ strongly agrees with $52.5 \%$ earlier reported in Ethiopia (WaretSzkuta et al., 2008). Tanzania also had a prevalence of 45.8 which also doesn't vary much from the observed overall prevalence from this study (Senyael et al., 2009). Explanation for the shooting seroprevalence of PPR in these districts can be due to misdiagnosis of the disease where the local Veterinarians used to confuse it with helminthosis, due to the closely similar clinical signs of the two diseases. Veterinarians complained that animals were not responding to antihelmetics.
This increased the levels of the disease not until the true diagnosis was established. Lack of quarantine of the infected animals (FAO, 1999) as the practice of nomadic pastoralism where the nomads from north western Kenya, the Turkanas, used to graze from these districts with their infected animals as pastoralists did not know anything about clinical signs and spread of the disease, hence mixing the infected with the non infected ones. Transmission of PPR virus involves close contact between susceptible and infected animals in the febrile stage (Braide, 1981) and therefore rampant practice of communal grazing and watering by pastoralists in Karamoja sub-region, is one of the reasons for the shooting PPR virus antibody levels revealed in this study. The discharges from eyes, nose, mouth and the loose feaces contain large amounts of virus. Fine droplets released in air from secretors and excretion, particularly when affected animals cough or sneeze (Taylor., 1984; Badza et al., 1988) and when animals in close contact inhale the droplets and are likely to become infected. Abim district had the lowest seroprevalence of PPR virus (1.6\% - $0.01-3.22)$ as compared to other districts in Karamoja sub-region this can be explained the fact that it is located in the interior of Karamoja Sub-region.

By the time this study was carried out, the disease had not spread much in the interior of Uganda and therefore, there is need for a nationwide surveillance program to ascertain the extent of spread of the PPR virus. More detailed and systematic study should also be carried out to ascertain the role of other species other than goats in the epidemiology of PPR in Uganda. The current research agrees with the results of the seroprevalence of PPR virus in the districts surrounding Karamoja sub-region recently published by Ruhweeza et al. 2010 showing that the disease has already spread in the surrounding districts of karamoja sub-region. There is a need to isolate and characterize the circulating PPR viruses in Uganda.

\section{Acknowledgement}

The authors are grateful to the ministry of Agriculture, Animal industry and Fisheries, Entebbe for offering laboratory space to complete this study. 
We are also indebted to the emergence control of PPR in Karamoja/Turkana ecosystem project (FAO/TCP/ RAF 3113(E) who funded this study.

\section{References}

1. Abraham G., Sintayehu A., Libeau G., Albina E., Roger F., Laekemariam Y., Abayneh D., Awoke K.M. (2005): Antibody seroprevalences against peste des petits ruminants (PPR) virus in camels, cattle, goats and sheep in Ethiopia Prev. Vet. Med., 70 (1-2):51-7.

2. Barrett T., Visser I.K.G., Mamaeu L., Goatley L., Bressem M.F., Van Osterhaus A.D.M. (1993): Dolphin and porpoise morbilliviruses are genetically distinct from phocine distemper virus. Virology, 193:1010-1012.

3. Badza A., Afshar A., Dukes T.W., Myers D.J., Dulac G.C. and Becker S.A., (1988): Experimental PPR (goat plague) in goats and sheep. Canadian J. Vet. Res., 52; 46- 52.

4. Braide, V.B. (1981): Peste des Petitis Ruminants. World Anim. Rev., 39; 25-28.

5. Chauhan H.C., Chandel B.S.,Kher H.N., Dadawala A.I. and Agrawal S.M. (2009). Pesti Des Petits ruminants virus infection in animals. Vet. World, 2(4): 150-155.

6. Furley C.W., Tylor T.W., Obi T.V. (1987): An outbreak of PPR in a Zoological Collection. Vet. Rec., 121: 443-447.

7. Gargadennec L., Lalanne A. (1942) : La peste des petits ruminants. Bull. Serv. Zoot. Epiz. AOF 5(1):16-21.

8. Gibbs, E.P.J., Taylor, W.P., Bryant, J., (1979) : Classification of Peste des Petits Ruminants virus as the fourth member of genus Morbillivirus. Intervirol. 11, 268-274.

9. Gilbert, Y., Monnier, J., (1962) : Adaptation des virus de la Peste des Petits Ruminants aux cultures cellularaires. Rev. d'Elev. Med. Vet. Pays trop. 15, 321-335.

10. Lefevre P.J., Diallo A., (1994) : Peste des Petits Ruminants. Rev. Sci. Tech.9: 51-65.

11. Lequin R., (2005): Enzyme immunoassay (EIA)/ enzyme linked immunosorbent assy (ELISA). Clin. chem. 51 (12): 2415-8.

12. Libeau G., Prehaud C., Lancelot R., Colas F., Guerre L., Bishop D.H.L., Diallo A., (1995): Development of competitive ELISA for detecting antibodies to the peste des petits ruminants virus using a recombinant nucleoprotein. Res.Vet.Sci. 58 (1): 50-55.

13. MAAIF, (2008): A summary report of the national livestock census. Ministry of Agriculture Animal Industry and Fisheries, Entebbe.

14. MAAIF, (2009): Final report: vaccination against PPR in goats and sheep, and CBPP in cattle in Karamoja region (LOA 085/08). Ministry of Agriculture Animal Industry and Fisheries, Entebbe, Uganda.

15. Misbah Aslam, et.al.(2009): Prevalence of Peste Des Petits Ruminants Virus (PPRV) in Mardan, Hangu and Kohat District of Pakistan; Comparative Analysis of PPRV Suspected serum samples using Competitive ELISA (cELISA) and Agar Gel Immunodiffusion (AGID). Vet. World, 2(3):89-92.

16. Murphy F.A., Gibbs E.P.J., Horzinek M.C., Studdert M.J.
(1999): Classification and nomenclature of viruses. In veterinary virology, 3:413.

17. Nussieba A. O., Ali A.S., Mahasin E. A/R., Fadol M.A. (2009): Antibody seroprevalences against Peste des Petits Ruminants (PPR) virus in sheep and goats in Sudan. Trop. Anim. Health and Prod. 41(7): 1449-1453.

18. OIE, (2002): World Organization for Animal Health. 70th General Session of the International Committee of the Office International des Epizooties.www.oie.int.

19. Dhar P., Sreenivasa B.P., Barrett T., Corteyn M., Singh R.P. and Bandyopadhyay S.K. (2002): Recent epidemiology of peste des petits ruminants virus (PPRV). Vet. Microbiol. 88: $153-159$.

20. Rita Narayanan, P. Gopu, S. Baegan, Barathidasan (2008): Clinical Management in an outbreak of Peste Des Petits Ruminants in Barbari Goats. Vet.World, 2008; 1(3):81-82.

21. Ruhweza S.P., Ayebazibwe C., Mwine F.N., Muhanguzi D., Mulindwa B., Olaho Mukani W. (2010): Seroprevalence of Peste Des Petits ruminants (PPR) virus antibodies in goats in North - East Uganda. Bull. Anim. Hlth. Prod. Afr.58 (2): 141 -146 .

22. Scott, G.R., (1981): Rinderpest and Peste des Petits Ruminants. In: Gibbs, E.P.J. (Ed.). Virus Diseases of Food Animals, Disease Monographs. Academic Press, New York, $2 ; 401-425$.

23. Senyael S.E., Kapaga A., Kivaria F., Tinuga D., Joshua G. and Sanka P. (2009): Prevalence and distribution of Peste des petitis Virus in various districts in Tanzania. Vet. Res. Comm. 10: $927-936$.

24. Sharawi S.S., Yousef M.R., Al-Hofufy A.N. and Al-Blowi M.H (2010). Isolation, Serological and Real time PCR diagnosis of Peste Des Petites Ruminants virus in naturally exposed Arabian Gazelle in Saudi Arabia. Vet. World, 3(11):489-494

25. Singh R. P., Sreenivasa B.P., Dhar P., Shah L.C. and Bandyopadhyay S.K., (2002): Development of a monoclonal antibody based competitive-ELISA for detection and titration of antibodies to peste des petits ruminants (PPR) virus. Vet. Microbiol. 98;3-15.

26. Sudharshan K.J., Rajasekhar M., Upadhye A.S. (1995): Prevalence of Peste des petits ruminants and rinderpes antibodies in small ruminants. Indian Vet. J. 72 (12):1246 1250.

27. Taylor W.P., (1984): The distribution and epidemiology of Peste des Petits Ruminants. Prev. Vet.Med.;2:157-166.

28. Wamwayi, H.M., Rossiter, P.B., Kariuki, D.P., Wafula, J.S., Barrett, T., Anderson, J., (1995): Peste des Petits Ruminants virus in Goats. Vet. Rec.: 136: 199-200.

29. Waret-Szkuta A., Roger F., David C., Yigezu I., Genevieve I., Dirk P. and Javier G. (2008): Peste Des Petits Ruminants (PPR) in Ethiopia, analysis of national serological survey. BMC Vet. Res. 4:34.

30. Yalow R., Berson S., (1960): Immunoassay of endogenous plasma insulin in man. J. clin. Invest. 39: 1157-75.

31. Yayehrad, TF, (1997): Doctor in Veterinary Medicine thesis Epidemiological survey of Peste des Petits Ruminants and Contagious pleuropneumonia in selected areas of Ethiopia. Debre Zeit Faculty of Veterinary Medicine. 